\title{
Manual therapy in the treatment of facial wrinkles and sagging: a quantitative-qualitative randomized clinical trial
}

\author{
Aline de Souza Massulo Garcia', Dilane Braga da Silva', Vanessa Daniele Ferreira Gonçalves', \\ Alessandra Couto de Camargo Ferreira'
}

\begin{abstract}
Background: Manual therapy has emerged as an option for facial rejuvenation treatment due to its effects on connective tissue. Objectives: The aim of the study was to verify the effectiveness of the manual therapy protocol in attenuating wrinkles and facial sagging. Methods: This is a quantitative-qualitative, randomized clinical trial. The study included female volunteers, aged between 40 and 50 years, distributed in 2 groups: Manual therapy group (MTG) and Control group (CG). The protocol used consisted of: lymph node decongestion, sliding massages, fast and vigorous movements, and traction on the fasciae. The evaluation instrument was through photos, in which they were analyzed by Dermato-functional specialists through a scale that graduates the wrinkles. The Shapiro-Wilk normality test was used to analyze the symmetry of the results by the Gauss curve. Pre- and post-intervention differences between the groups were determined using the non-parametric Wilcoxon test. Results: The average score obtained in the graduation of wrinkles and signs of aging in the manual therapy group showed significant differences in all regions of the face before and after treatment. And there was a decrease in the score, which shows improvement in the reduction of wrinkles and signs of aging, especially in the upper third. In contrast, in the control group, the average remained before and after the follow-up by the research, showing that there were no significant changes in this group. Conclusion: The manual therapy protocol showed significant results in reducing the signs of aging, such as fine lines and wrinkles, being another option to be applied in clinics.
\end{abstract}

Keywords: Facial Rejuvenation; Manual Therapy; Aging; Facial Wrinkles; Sagging.

\section{INTRODUCTION}

The face is the region of the body where one can most easily detect the aging process. It is through the face that the human being expresses feelings and emotions such as happiness, anger and sadness. However, with advancing age, poor habits and lack of skin care lead to superficial or profound damage that causes deformation and skin aging $^{1}$. The characterization of facial aging is mainly by changes on the skin, facial expression muscles and muscle fascia resulting in sagging tissues and wrinkles formation. The superficial muscular aponeurotic system (SMAS), which consists in the continuation of the aponeurotic fasciae that line the muscles throughout the human body, is another affected system where the appearance of facial grooves and ptosis occurs, as it is responsible for sustaining facial tone by being directly adhered to the skin. Thus when pulled the SMAS causes lifting effect due to indirect skin traction².

An affordable resource used in physical therapy to minimize the signs of facial aging is manual therapy. Manual therapy is not just a modality for the use of passive mobilization techniques, there are several techniques that physiotherapists use such as soft tissue massage, proprioceptive neuromuscular facilitation, segmental stabilization, high-speed manipulation, joint mobilization and fascia mobilization ${ }^{3}$. Nevertheless, there is a lack of studies that use manual therapy in the treatment of facial aging, therefore, studies are needed to prove the effectiveness of manual therapy in facial rejuvenation, as this may be another resource to be used safely and effectively in the Dermato-functional Physiotherapy ${ }^{2}$. Therefore, the objective of this study was to verify the effectiveness of the manual therapy protocol in attenuating wrinkles and facial sagging.

\section{METHODS}

This is a quantitative-qualitative, randomized clinical trial. The population involved in this study was female volunteers, aged between 40 and 50 years old, who presented facial flaccidity, worked in an environment where there was no sun exposure, who did not use orthodontic appliances and who had not performed aesthetic procedures on their face. Volunteers who had some dermatological pathology, smokers, alcoholics, pregnant women, who did not provide sufficient time for the execution and participation of the procedures proposed by the researchers, and those who did not agree or were not interested in completing the procedures, were

Correspondence: Aline de Souza Massulo Garcia. Address: Rua Angélica, 360, Jardim Santarém, Santarém/Pará. E-mail: linnydnmassulo@hotmail.com Phone number: +55 (93) 992302560

${ }^{1}$ Physiotherapy Course, Instituto Esperança de Ensino Superior - IESPES, Santarém, Pará, Brazil.

Financial Support: Nothing to declare

Submission date 21 November 2019; Acceptance date 15 December 2019; Publication date 30 December 2019 
excluded. The sample consisted of 16 women, randomly divided into manual therapy group (MTG; $n=9$ ) and control group (CG; $\mathrm{n}=7$ ).

After approval by the Ethics Committee (No. 3.429.785), the volunteers were screened according to the exclusion and inclusion criteria, and were clarified about the research objectives, methodology and procedures. Upon admission of each volunteer, the Informed Consent Form was applied to participate in the research. During the research two volunteers stopped participating in the study and the control group was reduced to five patients. All research groups received a basic homecare care kit consisting of neutral liquid face soap and active-free SPF 50 sunscreen and were oriented on use. They also attended 4 lectures lasting 30 minutes every 15 days on the following subjects: Skin care; Food: Take care from the inside out; Moisturize your face skin: Understand why it is essential to add habit to your beauty and facial self-massage routine.

Only the manual therapy group received the facial massage sessions, the protocol used consisted of: decongestion of the retro-auricular, submental, submandibular and cervical lymph nodes, followed by lymphatic drainage of the entire face, immediately after, the sliding massages began in the upper, middle and lower third of the face and neck according to the muscle fibers through fast and vigorous movements, and traction on the fasciae. The protocol was applied 3 times a week for 6 weeks, totaling 16 sessions. Each session lasted an average of 40 minutes.

The photographs were taken before and after treatment by a Canon 60D digital camera, 18 megapixels, in a room with ambient lighting and dark background. The photographic record was standardized in the front, right and left profile positions. The patients remained seated at a distance of $30 \mathrm{~cm}$ from the back and $90 \mathrm{~cm}$ from the camera. The volunteers were instructed to come without makeup on the day of evaluation and reevaluation. In addition to the photograph, it was applied the Assessment Sheet based on the Facial Assessment Protocol validated by Micussi et.al., ${ }^{4}$ and a satisfaction questionnaire to participate in the research prepared by the authors. The photographs were printed and randomly distributed to 5 blind evaluators specializing in Dermato-functional Physiotherapy, who assessed the wrinkles and signs of aging of the upper, middle and lower third of each volunteer using a grading scale: (0) absent, (1) mild, (2) moderate and (3) severe, based on the study of Franzão and Manzi ${ }^{5}$.

Data were entered, organized and processed using descriptive statistics in Excel spreadsheets (Microsoft Office ${ }^{\circledR}$ 2016). The results were submitted to the Shapiro-Wilk normality test to analyze the symmetry of the results by the Gauss curve. Pre- and post-intervention differences between manual therapy and control were determined using the nonparametric Wilcoxon test, as the data did not admit normality. Intergroup differences were determined using the Mann-Whitney test for nonparametric data. Nominal categorical data were submitted to Fisher's exact test to prove the independence of two small samples, classified on two criteria. The null hypothesis rejection level was set at 0.05 or $5 \%$. The tests were performed using the Bioestat 5.0 program and statistical data were presented as tables and graphs.

\section{RESULTS}

At Table 1, the average score obtained in the graduation of wrinkles and signs of aging in the manual therapy group showed significant differences in all regions of the face before and after treatment. And there was a decrease in the score, which shows improvement in the reduction of wrinkles and signs of aging, especially in the upper third. In contrast, in the control group, the average remained before and after the follow-up by the research, showing that there were no significant changes in this group.

When comparing the mean values obtained in the initial assessment through the grading scale of wrinkles and signs of aging between the manual therapy group and the control group, it was verified that there was no difference between the groups $(p=0.1320)$, which denotes that initially the samples were homogeneous. When compared to the variance of mean grading of wrinkles and signs of aging between the manual therapy and control groups before and after follow-up by the research, it was observed that there were significant intergroup differences, since only in the manual therapy group there was a reduction in the mean values of the graduation scores of wrinkles and signs of aging, the control group maintained the values without change, as shown in Figure 1. Regarding the analysis of patient satisfaction after the intervention and the follow-up by the research, it can be seen in Table 2 that most patients in both groups showed to be satisfied with the procedures, as most stated to notice improvement in skin lines and/or appearance and that the treatment exceeded expectations.

All patients would indicate and continue treatment and believe the treatment was effective. The difference between the control and manual therapy groups was in the sense of

Table 1. Intra-group mean grading values of wrinkles and signs of aging before and after the follow-up by research according to the treatment areas.

\begin{tabular}{lllll}
\hline \multicolumn{1}{c}{ Groups } & & Before & After & Value of $\mathbf{p}$ \\
\hline \multirow{3}{*}{ Manual } & Upper third & $01.8 \pm 0.6$ & $01.2 \pm 0.6$ & $<0.0001^{*}$ \\
Therapy & Middle third & $02.2 \pm 0.7$ & $01.8 \pm 0.8$ & $<0.0141^{*}$ \\
& Lower third & $02.0 \pm 0.7$ & $01.7 \pm 0.7$ & $00.0129 *$ \\
Control & Upper third & $01.6 \pm 1.2$ & $01.6 \pm 0.9$ & 11.000 \\
& Middle third & $11.8 \pm 0.7$ & $21.8 \pm 0.7$ & 00.7353 \\
& Lower third & $21.9 \pm 0.7$ & $21.9 \pm 0.8$ & 10.7897 \\
\hline
\end{tabular}

Note: *Significant result for Wilcoxon test $(p \leq 0.05)$ 
Table 2 - Distribution of treatment satisfaction responses from the manual therapy.

\begin{tabular}{|c|c|c|c|}
\hline Questions & & & p \\
\hline 1. What aspects of improvement did you notice after treatment? & Manual Therapy & Control & \multirow{3}{*}{$p=0.357$} \\
\hline Improved expression lines and / or skin appearance & $7100 \%(n=9)$ & $80 \%(n=4)$ & \\
\hline No improvement & $0 \%(n=0)$ & $20 \%(n=1)$ & \\
\hline \multicolumn{4}{|l|}{ 2. Did the treatment exceed your expectations? } \\
\hline Yes & $88 \%(n=8)$ & $75 \%(n=4)$ & \multirow{2}{*}{$p=1.000$} \\
\hline No & $11 \%(n=1)$ & $25 \%(n=1)$ & \\
\hline \multicolumn{4}{|l|}{ 3. What did it feel like to receive this kind of aesthetic treatment? } \\
\hline Well-being & $100 \%(n=9)$ & $40 \%(n=2)$ & \multirow{2}{*}{$p=0.0275^{*}$} \\
\hline Normal & $0 \%(n=0)$ & $60 \%(n=3)$ & \\
\hline \multicolumn{4}{|c|}{ 4. Did you feel any unpleasant feeling when receiving this aesthetic treatment? } \\
\hline Yes & $0 \%(n=0)$ & $0 \%(n=0)$ & \multirow{2}{*}{$p=1.000$} \\
\hline No & $100 \%(n=9)$ & $100 \%(n=5)$ & \\
\hline \multicolumn{4}{|l|}{ 4. Would you indicate this treatment? } \\
\hline Yes & $100 \%(n=9)$ & $100 \%(n=5)$ & \multirow[t]{2}{*}{$p=1.000$} \\
\hline No & $0 \%(n=0)$ & $0 \%(n=0)$ & \\
\hline \multicolumn{4}{|l|}{ 5. Would you continue the aesthetic treatment? } \\
\hline Yes & $88 \%(n=8)$ & $100 \%(n=5)$ & \multirow{2}{*}{$p=1.000$} \\
\hline No & $11 \%(n=1)$ & $0 \%(n=0)$ & \\
\hline \multicolumn{4}{|l|}{ 6. Do you believe this treatment can be effective? } \\
\hline Yes & $100 \%(n=9)$ & $100 \%(n=5)$ & \multirow{2}{*}{$p=1.000$} \\
\hline No & $0 \%(n=0)$ & $0 \%(n=0)$ & \\
\hline
\end{tabular}

Note: *Significant result for Fisher's Exact test ( $p \leq 0.05)$.

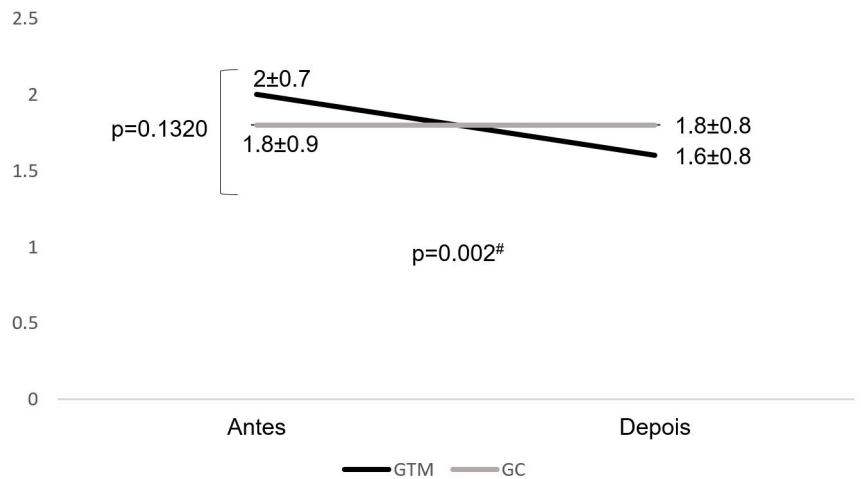

Figure 1. Intergroup comparison of variance of grading mean of wrinkles and signs of aging before and after the follow-up by research. Note: Antes = Before; Depois: After; GTM: Manual therapy group; GC: Control group. Significant result for Mann-Whitney test.

well-being with the aesthetic treatment offered, mostly the manual therapy group reported well-being, and in contrast the control group reported normal sensation.

\section{DISCUSSION}

This study aimed to elucidate the effects of manual therapy techniques in the treatment of facial wrinkles and sagging, considering that this aesthetic dysfunction is recurrent in Dermato-functional Physiotherapy clinics. Manual therapy techniques are specific manipulations, mobilizations and exercises aimed at stimulating proprioception, producing elasticity of adhered fibers, stimulating synovial fluid and promoting pain reduction ${ }^{6}$. Massage promotes a mechanical exfoliation, removing cells from the stratum corneum of the epidermis, stimulating blood and lymphatic circulation, causing skin hyperemia, enlargement of the dermis capillaries, which favors tissue nutrition and removal of its catabolites, clears the pores, and causes the skin hydration and smooth appearance ${ }^{7,8}$.

The effects of massage were observed in this research, with the improvement of skin appearance and reduction of wrinkles in MTG. A similar randomized controlled trial using the traction protocol, myofascial release, and connective tissue modeling across the face, lasting 30 minutes, totaling 16 sessions, also observed through photogrammetry the clinical improvement of wrinkles, corresponding to $73.3 \%$ in the control group and $87 \%$ in the massage group ${ }^{2}$.

Similar results were found in the experimental clinical research that used a protocol with in natura products and stimulating massage in women aged $34-60$ years and at the end of the research showed skin softness and reduction of expression lines ${ }^{9}$. In another study of the uncontrolled experimental clinical trial conducted with six female patients aged $50-55$ years, found that all participants had deep static wrinkles and at the end there was a modification for superficial static wrinkles. The treatment consisted of 10 sessions performed twice a week for skin cleansing, connective tissue massage with quick and vigorous maneuvers and finishing with sunscreen ${ }^{10}$. 
However, regarding the photographic records, no significant changes were observed, unlike what was found in the present study in which there were significant changes in the face before and after the treatment analyzed through photographs, this factor may be due to the greater number of sessions or younger age group of the target audience, which may have favored better results ${ }^{10,11}$.

Still regarding the above study, all 6 patients reported through the visual satisfaction scale improved treatment and higher self-esteem ${ }^{10}$. When the satisfaction with treatment scale was analyzed, it was also found that most patients, both in manual therapy and control group, showed to be satisfied with the procedures.

It is known that although the control group did not undergo manual therapy sessions, patients were followed for skin care and encouraged to use liquid soap and sunscreen daily, which possibly allowed the wrinkles and signs of aging not to get worse, keeping the averages without significant variation. The importance of daily care, especially regarding protection against ultraviolet rays, is due to the sun's oxidative damage and its ability to cause photoaging through the formation of free radicals causing changes in the dermis ${ }^{11}$.

Thus, because the research also provided the control group with daily basic care, all patients would indicate and continue treatment. The difference between the control and manual therapy groups was in the sense of well-being with the aesthetic treatment offered, mostly the manual therapy group reported well-being, in contrast the control group reported normal sensation. The feeling of well-being reported by MTG patients is justified due to massage being able to decrease the levels of cortisol, the stress-related hormone, in the body. There is also the release of hormones such as dopamine and serotonin, which are related to feelings of happiness and well-being in humans ${ }^{12}$.

When comparing the results of this research with other methods for facial rejuvenation, we found that the radiofrequency technique also presents good results, as in the experimental study in which 10 radiofrequency sessions showed a significant decrease in wrinkle areas $(p=0.016)$, improved skin color and texture, as well as participant satisfaction ${ }^{13}$.

It is noteworthy that the radio frequency technique requires equipment with significant cost when compared to manual techniques, thus, comparing the results of the present study through manual therapy with facial exercises and the systematic review with 9 studies by Borsel et al., it is highlighted the effectiveness of facial exercises for facial rejuvenation. Although positive results were achieved, none of the studies used a control group and a randomization process, which degrades the methodological and comparative quality of the actual effects of the exercises ${ }^{14}$.

\section{CONCLUSION}

It can be concluded that manual therapy in facial rejuvenation showed significant results in attenuating the signs of aging, such as wrinkles and fine lines, whitening, improvement in skin appearance and tone. And manual therapy, although simple and inexpensive, has had satisfactory results because of the effects massage provides, such as skin relaxation, tissue nutrition, circulation improvement, and stimulation of collagen and elastin synthesi. Further studies are needed to contribute to new research samples with the academic community and aesthetic professionals.

\section{AUTHORS' CONTRIBUTIONS:}

ASMG, DBS, VDFG and ACCF elaborated the study design; ASMG, DBS and VDFG performed data collection; ACCF performed the statistical analysis and guided the research; ASMG, DBS, VDFG and ACCF undertook the critical intellectual revision of the manuscript. All authors read and approved the final manuscript.

\section{CONFLICT OF INTEREST:}

Nothing to declare.

\section{REFERENCES}

1. Santos IML, Meija DPM. Abordagem fisioterapêutica no envelhecimento facial. Pós-graduação em Dermato-Funcional-Faculdade Ávila. 2013.

2. Silva RMV, Daams EFCC, Delgado AM, Silva EM, Oliveira HG, Meyer PF. Efeitos da terapia manual no rejuvenescimento facial. Rev.Ter Man, 2013;11(54): 534-539.

3. Vieira AKM, Souza FGL. Benefício da Liberação miofascial no tratamento da fascite plantar. Pós-graduação em Fisioterapia em Ortopedia e Traumatologia com ênfase em terapias manuais-Faculdade Faserra. 2018.

4. Micussi MTA, Oliveira TCM, Meyer PF, Araújo FRO. Protocolo de avaliação facial: uma proposta fisioterápica. Revista Fisioterapia Brasil, Suplemento Especial-2008.

5. Franzão Y, Manzi SB. Eficácia Da Intervenção Fonoaudiológica Para Atenuar O Envelhecimento Facial. Rev. CEFAC, 2012;14(4):755-762.

6. Araújo FG. Técnicas de terapia manual: definições, conceitos e princípios básicos: Uma revisão bibliográfica. Pós-graduação em Fisioterapia Traumato-ortopedia com ênfase em Terapia Manual Faculdade Ávila. 2012.

7. Kleina A, Oliveira SP. Os Efeitos Fisiológicos Da Massagem Miofascial Na Prevenção De Rugas. Curso De Tecnologia Estética E Imagem Pessoal Da Universidade Tuiuti Do Paraná, 2015.

8. Neves PA, Quadros JF, Macedos ACB. Efeito Da Aplicação Da Massagem Modeladora E Ultrassom Na Região Abdominal Em Mulheres Sedentárias. Cadernos da Escola de Saúde, Curitiba, 2013;11:128-38.

9. Fagundes FC, Eugênio JN, França AJVBDV, Piazza FCP. Tratamento Estético Facial Para envelhecimento cutâneo com Componentes In Natural. Curso de Cosmetologia e Estética da Universidade do Vale Itajaí-UNIVALI, Balneário Camboriú, Santa Catarina. 2011.

10. Almeida AP, Delgado D, Luchesa CA. Massagem Estética Facial Na Atenuação Das Rugas Em Mulheres Saudáveis Entre 50-55 Anos. Movimento \& saúde REVISTA INSPIRAR, 2013;5(6):27.

11. Gobbo, P. Estética facial essencial: orientação profissional para o profissional de estética. SP: Atheneu, 2010.

12. Viana LS, Passos RM, Leitão CSS, Damasceno K. S. Aplicação Da Massagem Sueca Na Estética. Revista de Produção Acadêmico-Científica, Manaus, v.4, n.․ 22017.

13. Facchinetti JB, Souza JS, Santos KTP. Radiofrequência no Rejuvenescimento Facial. Id on Line Revista Multidisciplinar e de Psicologia, 2017;11(38):336348.

14. Van Borsel J, De Vos MC, Bastiaansen K, Welvaert J, Lambert J. The effectiveness of facial exercises for facial rejuvenation: a systematic review. Aesthetic surgery journal, 2014;34(1): 22-27. 